the book will be of most use to those who wish to dip into the relationship between law, ethics and medicine without being overwhelmed by detail. It should not be seen as taking such a person too far as it does not provide a comprehensive study and is weighted towards the state of New York. Nevertheless, it will provide much food for thought.

JONATHAN MONTGOMERY Faculty of Law University of Southampton, England

\section{Ethical Dilemmas In Health Promotion}

Edited by Spyros Doxiadis, 234 pages, Chichester, £38.00, John Wiley and Sons, 1987

This is a book to be welcomed since it puts philosophical issues surrounding the area of health promotion firmly into the arena for discussion, alongside the more traditional areas of practice, economics, training and so on. Up to now, it has been hard for students and practitioners in the field of health to have easy access to the kinds of arguments and processes which ought to be part of their everyday questioning about their professional practice, and this book goes some way towards identifying some of the main issues and the ways in which we might begin to think about them.

Having said that, I want to qualify my comments. I believe that this book will prove to be extremely useful as an initial publication in the debate but, because it is early days, there seems to be no overall framework within which the various contributions can be placed. The general bias in the book, whether through the professional training or present perspectives of the authors is towards medicine, with a model of health which is about illness, its prevention or cure, and about a normative model of practice which postulates, overtly or covertly, an expertise whose basis - that medical knowledge equals health - is never fully examined. There are some assumptions and assertions which merit more rigorous critical treatment in a book which is likely to carry a great deal of weight. Rayner, for example, asserts that health education is about the giving of information and messages which may be positive or negative (my emphasis), implying a power relationship which many health educators would want to question; whilst many of the other authors seem to use the terms 'health promotion', 'health education', 'medicine' and 'prevention' as if the concepts to which these labels are attached were interchangeable, with no difference in meaning. Conceptual woolliness of this kind is a disappointment from such an impressive array of authors.

But these criticisms are, I think, merely indicative of the 'state of the art' and further debate, likely to be stimulated by this publication, will challenge and refine the arguments. There is much here which is thoughtprovoking, and likely to generate feelings of dissonance in the reader never a bad thing for those of us who claim to be working in other people's interest! In general, the style of writing is clear and easy to read - crucially important if health professionals new to philosophy are to be encouraged to 'read on'. Above all, the book embraces a range of issues which have relevance at micro and macro levels, enabling us to engage in our own problems as well as considering a world view. It thus challenges us to focus on our own work yet forces us to acknowledge our wider responsibilities. Definitely 'essential reading' for any postgraduate course for health professionals of all kinds; I just hope that the readership won't be confined to such groups, but that all those interested in improving health will read it.

GILL WILLIAMS Lecturer in Health Education, recently retired, King's College University of London

\section{Child Psychiatry and the Law}

Edited by Dora Black, Stephen

Wolkind and Jean Harris Hendriks, 178 pages, London, $£ 10.00$, Gaskell/ Royal College of Psychiatrists, 1989

The Royal College of Psychiatrists has continued its excellent series of practical and important books on topics in clinical psychiatric practice, with this, the first book in its series oriented towards child psychiatrists. It is a pity that this book should be published when the legal information in it is about to be rendered obsolete by the implementation of the Children Act 1989. In spite of this, there is a fund of information clearly laid out and adequately indexed to make possession of this publication essential to British child psychiatrists and paediatricians, and of use to others concerned in the care and rights of children.

In recent years, child psychiatrists have frequently been called on, both by the courts and local authorities, to give an expert opinion, from knowledge of clinical and research experience, about the best interests of children with whom they have been concerned. The anxiety created in the public domain by the exposure of the extent to which children are abused, both by their parents and carers, the relative neglect of their interests, and a change in the emphasis of the law from the preoccupation with the child as the property of the parent, to a person with individual rights of its own, has led to a situation where the skills of the child psychiatrist to deal with the resulting decision and anxiety, is increasingly called on.

By discussing the tasks of the child psychiatrist exposed to the demands of the legal professional discipline, and the practical aspects of the child psychiatrist's appearance in the legal system, this book provides a means whereby many of the pitfalls can be avoided. The child psychiatrist is made aware of the need to defend opinions and statements, which must enrich general clinical experience and practice

Section two of the book, by giving examples of actual court reports, indicates the different styles of report which might be available to a practitioner, while the check-lists at the end of each chapter provide a most useful reminder when writing reports, or considering their presentation. The chapter on fees gives pointers for those whose knowledge of the private sector is very limited, but omits to mention that the BMA issues guidelines as to fees payable for Section 2 work and court appearances.

The chapters on confidentiality are concise and define the responsibility the child psychiatrist has to the child, rather than to the parents or to the agency which solicits the report. Most reports about children are necessarily reports about the family in which the care of the child has broken down, which has resulted in the child's appearance in the legal system. There is inadequate discussion of the rights of the parents in such a system.

The area which causes greatest anxiety, namely appearance in court, when an expert witness is subjected to cross-examination, is addressed. It might have been helpful if: i) further discussion of the experience of evidence-giving had been included, and 
ii) some discussion of the techniques of advocacy to which the expert witness might expect to be subjected, had been provided. David Cook did just this in his article, 'Being an expert witness', which was published in The Psychologist, in May 1990.

One must look forward to the complete rewriting of this publication which is necessitated by the implementation of the Children Act in October.

See also the excellent, Professionals and the Courts - a Handbook for Export Witnesses by David Carson, published by Venture Press, Leicester with the BASW, 1990.

DR CONSTANCE M DENNEHY Department of Family $\mathcal{G}$ Child Psychiatry

Queen Elizabeth's Hospital for Children Hackney Road London E2 8PS

\section{Teaching Genetics to Medical Students}

Working party of the Committee on Clinical Genetics of the Royal College of Physicians, 32 pages, London, $£ 5.00$, Royal College of Physicians, 1990

The last few years have seen a rapid expansion in knowledge about genetic factors in disease, and also the introduction of many new genetic technologies of actual or potential clinical relevance. The process shows no sign of any slowing down, so this report, produced by a Working Party of the Committee on Clinical Genetics of the Royal Physicians of London, is timely. The report is short and succinct, and its message is clear.

The report reviews current medical undergraduate teaching in genetics at different centres in Britain. Only a small amount of timetabled teaching time is alloted to genetics, the average being a total of around 20 hours during the five-year curriculum. There was wide variation between centres on both the course content and the teaching time, but in almost all medical schools the majority of the genetics teaching formed part of the pre-clinical course.

While recognising that the medical undergraduate curriculum is already overcrowded, the working party concluded that there was an unambiguous and pressing need for the establishment of carefully co-ordinated and clearly delineated genetics teaching in medical schools. They go on to define topics for pre-clinical genetics teaching, and make strong recommendations for strengthening and co-ordinating genetics teaching during the clinical course. A draft syllabus and suggested teaching methods for the clinical course are given in an appendix.

If there is to be more and better teaching, there will need to be an expansion in the numbers of clinical genetics teachers. The report concludes by recommending a task force should be set up to accelerate the pace of change in genetic education.

The introduction of both genetic screening and new technologies has already highlighted many ethical problems. If gene therapy becomes a practical possibility there will be new ethical issues to consider. It was pleasing to see that in a survey of clinicians an appreciation of the major ethical issues in medical genetics and an awareness of the stress caused in families by genetic disease were ranked highly as skills that needed to be taught to clinical students.

Reports are not self-executive. The next steps are awaited with interest.

RICHARD WEST

Consultant and Senior Lecturer Department of Child Health, St George's Hospital, London SW17 ORE

\section{A Casebook of Medical Ethics}

T F Ackerman and C Strong, 240 pages, New York, £32.00, Oxford University Press, 1989

This book consists of a series of medical case histories which can be considered and discussed. The cases were chosen because they posed difficult moral problems for the doctors involved to consider in deciding how to act in managing of each case. Every case description contains a wealth of detail, including many of the complexities of the patient's personal circumstances and a full account of the medical issues involved. Almost all are actual cases of which the authors have personal knowledge.

The cases are grouped together into chapters with a common theme, covering the topics of paternalism, duties to the patient and the family, making decisions for others, medical research, and doctors and third parties.
As well as the case histories, there is a commentary at the end of each chapter which provides guidance on the moral principles involved in the cases.

None of the case histories given are straightforward, either from a medical or a moral perspective. It is fortunate that in practice not all clinical problems pose the same difficulties!

There is no doubt that many teachers and students will benefit from having this source of very detailed case descriptions to consider and discuss together. Analysing each history provides insight into ethical principles and demonstrates that in practice there are often complicating factors that have to be taken into consideration, including the uncertainties inherent in both medicine and ethics. The moral principles involved in each case often appear to be conflicting, and make clear the difficulties faced by the practising doctor.

Of great value are the authors' commentaries at the end of each chapter, which analyse the problems and show ways towards the resolution of the ethical dilemmas that are posed in various situations.

This book is a useful addition to the medical ethics literature both because of the well documented and interesting case histories, and for the commentaries which are lucid and informative. Though mainly of use for those either teaching or learning about health care ethics it will also appeal to medical practitioners, nurses and other health care workers interested in good clinical practice.

RICHARD WEST Consultant and Senior Lecturer Department of Child Health, St George's Hospital Medical School, London SW17

\section{Changing Ideas in Health Care}

Edited by David Seedhouse and Alan Cribb, 236 pages, Chichester, £9.95, John Wiley and Sons, 1989

This book contains a collection of articles which describe attempts to facilitate increased public participation in health care. These have taken place in a variety of social settings including a national heart-health education programme; city and community-based initiatives; and hospital and hospice 